\title{
Lung cancer in Brazil: epidemiology and treatment challenges
}

This article was published in the following Dove Press journal:

Lung Cancer:Targets and Therapy

14 November 2016

Number of times this article has been viewed

\author{
Vanessa Karen de Sál,2 \\ Juliano C Coelho ${ }^{3}$ \\ Vera Luiza Capelozzi' \\ Sergio Jobim de Azevedo 3 \\ 'Department of Pathology, \\ Faculty of Medicine, University \\ of São Paulo, ${ }^{2}$ Department of \\ Genomics and Molecular Biology, \\ International Research Center, \\ A.C. Camargo Cancer Center, São \\ Paulo, ${ }^{3}$ Department of Oncology, \\ Clinical Research - UPCO, Hospital \\ de Clínicas de Porto Alegre, Porto \\ Alegre, Rio Grande do Sul, Brazil
}

Correspondence: Vanessa Karen de Sá Department of Genomics and Molecular Biology, International Research Center, A.C. Camargo Cancer Center, Rua Taguá, 440, First Floor, CEP 01508-010, São Paulo, Brazil

Tel +55 II 21895023

Fax +55 II 21895025

Email vanessa.karen@cipe.accamargo.org.br
Abstract: Lung cancer persists throughout the world as a major cause of death. In 2014, data from the Brazilian National Cancer Institute (INCA) estimated 16.400 new cases of lung cancer among men (second most common) and 10.930 new cases among women (fourth most common). These data are consistent for all Brazilian regions and reflect the trends of cancer in the country over the last decade. Brazil is a continental country, the largest in Latin America and fifth in the world, with an estimated population of $>200$ million. Although the discrepancy in the national income between rich and poor has diminished in the last 2 decades, it is still huge. More than $75 \%$ of the Brazilian population do not have private health insurance and rely on the national health care system, where differences in standard of cancer care are evident. It is possible to point out differences from the recommendations of international guidelines in every step of the lung cancer care, from the diagnosis to the treatment of advanced disease. This review aims to describe and recognize these differences as a way to offer a real discussion for future modifications and action points toward delivery of better oncology care in our country.

Keywords: NSCLC, screening, drivers mutations, diagnosis, Brazilian scenario

\section{Epidemiology}

Cancer is a major public health problem worldwide and is currently the second leading cause of death, after cardiovascular diseases, which it is expected to surpass in the next years. The overall estimate for 2015 is $\sim 1.5$ million new cases in the US and $>500,000$ in Brazil. ${ }^{1,2}$ Lung cancer is the second leading cancer in men and women, but it is by far the most common cause of death in both sexes. In 2014, data from the Brazilian National Cancer Institute (INCA) estimated 16,400 new cases of lung cancer among men (second most common) and 10,930 new cases among women (fourth most common). These data are consistent for all Brazilian regions and reflect the trends of cancer in the country over the last decade. ${ }^{2}$

In contrast with developed countries, where lung cancer rates in men increased until the 1990s and decreased thereafter, in Brazil, they are still rising. Trends in the ageadjusted mortality rate revealed an increase from 10.6/100,000 to 13.1/100,000 among men and from 3.0/100,000 to 5.4/100,000 among women from 1979 to 2004. Although lung cancer mortality is significantly higher among men, data are pointing to a greater increment in the relative variation in mortality among women. The increase in mortality from lung cancer is detected in all age strata in both sexes, except for men aged 30-69 years. Since lung cancer has a long latency period from exposure to tobacco to the development of the disease, the real impact of the anti-tobacco campaign 
takes years to be reflected in the population data. The lung cancer mortality essentially reflects the tobacco habits of the Brazilian population in the last decades and not the real consumption nowadays. ${ }^{3}$

Since lung cancer is mostly tobacco related, the trends in incidence mortality are highly influenced by the prevalence of smokers in the population over the years. Smoking behavior drastically increased after World War II and achieved its peak in the 1970s. As a direct effect of tobacco control measures implemented by the Brazilian government, active smoking rates are strongly declining. The first large population-based study evaluating the prevalence of smokers in Brazil after the implementation of the tobacco control program estimated a decline of $35 \%$ between 1989 and 2003, albeit $>20 \%$ of the population are still actively smoking. ${ }^{4}$ More recently, in 2008, another population-based study confirmed the trend of decreasing rate of smokers, still with $\sim 17 \%$ of active smokers. $^{5}$

The success in the campaign for tobacco control is unequivocal, and the authorities are projecting a further annual reduction in smoking population, expecting a prevalence of $11 \%$ by $2020 .{ }^{4}$ Both the decline in prevalence and the reduction in the intensity of smoking tended to be stronger among males, younger age groups and higher socioeconomic strata. There is high concern regarding the women, because although the active smokers are declining, in some Brazilian cities, girls smoke more than boys do..$^{3,4,6}$

\section{Lung cancer screening}

The National Lung Cancer Screening Trial (NLST) recently demonstrated that low-dose computed tomography (LDCT) screening could effectively reduce lung cancer mortality among current and former heavy smokers. ${ }^{7}$ The NLST findings together with extrapolations of the trial to the US population led the US Preventative Services Task Force (USPSTF) to recently revise their assessment and recommendation for lung cancer screening for at-risk populations. ${ }^{8,9}$ The USPSTF now recommends, with a grade B recommendation, annual screening for lung cancer with LDCT in adults aged 55-80 years who have a 30-pack-year smoking history and are current smokers or have quit within the past 15 years. Consequently, it is expected that lung cancer screening will become prevalent across the US in the next decade. Although screening is anticipated to have a positive impact on reduction in lung cancer mortality in common with other cancer screening modalities, it will also likely to lead to overdiagnosis. ${ }^{10,11}$

In Brazil, screening is not recommended in the daily practice and the data are very limited. A major concern in the applicability and effectiveness of LDCT is the high rates of granulomatous disease in the country, where many pulmonary nodules can be secondary to an inflammatory cause. To address this question, dos Santos et al recently launched the First Brazilian Lung Cancer Screening (BRELT1), using the same inclusion criterion as that for the NLST: a pulmonary nodule $>4 \mathrm{~mm}$ was considered positive and required evaluation by a multidisciplinary team. Indeterminate nodules should be evaluated with fluorodeoxyglucose positron emission tomography (PET)/computed tomography (CT) or biopsy when indicated. ${ }^{12}$

In 2015, the results of the prevalence phase were published, and now the study is in the follow-up phase. From January 2013 to July 2014, 790 participants were enrolled. Positive LDCT scans were reported in 312 (39.4\%) participants, with a total of 552 nodules $>4 \mathrm{~mm}$. The comparison between positive findings in the NLST $(7,191$ of 26,722 cases) and those in the BRELT1 (312 of 790 cases) showed a significant difference $(P<0.001)$. The positive predictive value was lower in the BRELT1 than in the NLST (3.2\% versus $3.8 \%$, respectively). Follow-up imaging was indicated in 278 of 312 (89.1\%) participants; 35 procedures were performed in 25 participants. In 15 cases, benign lesions were diagnosed. Non-small-cell lung cancer (NSCLC) was diagnosed in 10 patients (prevalence of $1.3 \%$ ). In 8 patients (stage IA/IB disease), treatment was by resection only; in 1 patient, neoadjuvant chemotherapy was used (stage IIIA) and in 1 patient, advanced disease was diagnosed (stage IV). It was concluded that using NLST criteria, a larger number of patients had positive scans (nodules), compared with previous lung cancer screening studies. However, the number of participants requiring surgical biopsy procedures and who were ultimately identified as having cancer was similar to other reports. This supports the role of screening in patient populations with a high incidence of granulomatous disease, as in Brazil. ${ }^{12}$

Although the data from the BRELT1 support lung cancer screening in a high-risk population, the implementation of this strategy as a public health practice is not simple. In Brazil, most of the population are not instructed about disease prevention and usually arrive in the health system with high grade and symptomatic disease. Another concern is the difficulty to get good quality scans, sometimes with a longer waiting list ( $>3$ months). PET/CT or thoracic nodule biopsy is limited to tertiary hospitals, not available in many Brazilian regions. For all these issues, the government and medical societies have directed efforts to tobacco control campaign instead of lung cancer screening. 


\section{Treatment}

A comprehensive clinical and pathological investigation is essential to determine the correct staging and to define optimal treatment approach. All the cases should be discussed in a multidisciplinary cancer care board. Limited data from Brazilian patients about treatment outcomes are available in the literature. Most of these are retrospective reports from single institutions, and only 1 multicenter phase III clinical trial has been published.

\section{Early stage disease}

Surgical resection is the treatment of choice in all patients with stage I or II and good performance status. ${ }^{13}$

Despite complete resection, some patients may experience recurrence, and the survival depends heavily on the grade and stage of tumors at the time of the initial diagnosis. ${ }^{14}$ Adjuvant chemotherapy or radiotherapy may play a role for stage IB and II patients in the postoperative period.

Several prospective randomized trials confirm the survival advantage of adjuvant cisplatin-based chemotherapy with an absolute increment of 5\% for stage II or III patients. For stage I disease with tumors $>4 \mathrm{~cm}$, adjuvant therapy can also be beneficial. ${ }^{15-17}$ Postoperative radiation therapy should only be used for patients with positive surgical margins or N2 disease. Despite a better local control with the radiation treatment, its impact on survival is unclear. ${ }^{18}$ There is no benefit of radiotherapy for complete resected stage I patients.

There are 3 historical cohort reports ${ }^{19-21}$ on adjuvant treatment in Brazil in the literature. A retrospective cohort study performed in the National Cancer Institute - INCA included 51 stage I-III NSCLC patients treated with surgery and adjuvant chemotherapy from 2004 to 2008 . The mean age of the patients was 61 years, $53 \%$ were female, mainly had adenocarcinoma (57\%) and all had a good performance status ( 0 or 1$)$. Lobectomy was performed in $80 \%$ of the patients. Adjuvant chemotherapy regimen used was cisplatin + etoposide for up to 4 cycles. Stage 3 patients (27\%) received radiotherapy after the chemotherapy treatment. After a median follow-up period of 31 months, the median overall survival was 57 months and only $31 \%$ were alive after 5 years. Also, there was a trend, but without statistical significance, toward lower median survival in stage III patients when compared to those with stage I or II disease, with an overall survival of 34 months and 57 months, respectively. ${ }^{22}$ There are no data about the recurrence or the treatment used for advanced disease.

The other 2 studies included sequential patients (stages I-IV) evaluated in different private institutions. In the first one, a total of 566 patients were followed after surgery for a median follow-up time of 12.8 months. Surgery with curative intent was performed in 155 (28.1\%) patients. Of these patients, 67 received adjuvant therapy, and the median overall survival was 99.7 months for patients with stage I and 32.5 months for patients with stage II. ${ }^{23}$ The second study included 737 patients evaluated between 1990 and 2000. Complete resection was performed in 149 stage I-IIB patients. The median 5-year survival was 95 months for stage IB, 78 months for stage IIA and 73 months for stage IIB. ${ }^{24}$ Neither study provided information regarding epidemiological data, adjuvant therapy or recurrence in these patients.

\section{Locally advanced disease}

NSCLC stage III patients have several therapeutic options. Mediastinal pathological assessing is mandatory to determine the presence of lymph node metastasis. Some cases of stage IIIA with limited mediastinal disease could be managed with neoadjuvant therapy, while patients with bulky mediastinal disease or unresectable lesions should be treated with definitive chemoradiation. In the neoadjuvant setting, induction therapy with chemotherapy alone is preferred over chemoradiation, although the more intense treatment can be an option for the patient with an outstanding performance status. Clinical data are restricted, and most of the Brazilian trials have important limitations..$^{19,20}$

In Brazil, the information about neoadjuvant treatment in lung cancer is very poor and prospective studies are not available at this time. However, a phase II trial included 30 patients with stages IB-IIIA NSCLC from January 2001 to August 2002. All patients received 3 cycles of induction chemotherapy and reassessment for mediastinal lymph nodes. Those with negative mediastinal nodes were taken to surgery, and the positive ones were treated with definitive radiotherapy. Twenty-three patients had clinical response, including 8 out of $12 \mathrm{~N} 2$ patients. In 22 patients, surgery was performed, and 21 patients could have a complete resection. ${ }^{21}$ No data about survival were provided.

Patients with locally advanced or bulky mediastinal positive lymph nodes are better managed with a multimodality approach, including both chemotherapy and irradiation, and surgery is not recommended. Concurrent chemoradiotherapy is better than sequential treatment or radiotherapy alone. ${ }^{25,26}$ Although the combination of cisplatin and etoposide is widely used in this context, weekly carboplatin and paclitaxel, among others, is also popular. ${ }^{27,28}$ Both chemotherapy doublet agents are widely used in Brazil without any limitations.

Regarding the chemoradiation treatment in Brazil, in a retrospective study presented in the world conference of 
lung cancer in 2015, Coelho et al reported the outcome of chemoradiotherapy in a university hospital in the south of Brazil. Seventy-three patients with stage IIIA or IIIB NSCLC were treated with cisplatin-etoposide regimen concurrent to radiotherapy. Most patients were male (63\%), had a good performance status (89\%), and the most common histological type was adenocarcinoma (52\%). All patients were treated with etoposide-cisplatin concurrent with radiation, and 14 (19.2\%) received 2 consolidation cycles of chemotherapy. During a follow-up period of 15.7 months, 64 patients $(88 \%)$ had died, with a progression-free survival of 10.1 months and overall survival of 15.9 months. Clinical stage and performance status were independently associated with survival. ${ }^{29}$ The PARSIMONY study, a larger, multicenter, observational study, addressing this subject in the Brazilian population is expected to be present during the 2016 World Conference of Lung Cancer.

\section{Advanced disease}

The management of metastatic disease has changed drastically in the last years. Although rare patients with limited metastasis could be treated by an aggressive multimodality to try to achieve cure, in general, systemic palliative therapy is recommended. Initial complete evaluation with tissue diagnosis is mandatory, because the management will be individualized according to the histologic subtype. Patients with metastatic non-squamous lung carcinoma should have the tumor tested for driver mutations, such as EGFR, ALK fusion and ROS1. ${ }^{13}$

Metastatic patients without driver mutation in the tumor or when this information is unknown are candidates for cytotoxic chemotherapy with a platinum doublet for 4-6 cycles. This therapeutic approach not only increases the overall survival but also improves the quality of life regarding the cancer symptoms. Systemic chemotherapy should be offered even to asymptomatic patients. ${ }^{13,30}$

Brazilian data on stage IV NSCLC are also limited and based on individual center experience. There is a great heterogeneity of patients and drug regimens used in the treatment. In general, the overall survival was better than in those who received chemotherapy in comparison to best support of care, but considerably lower than in those reported in the literature. ${ }^{23,24,31-33}$ There are no data regarding maintenance therapy in the Brazilian population.

A retrospective observational study analyzed the data of 564 metastatic NSCLC patients treated between 1990 and 2003 in 3 different cancer centers in São Paulo. The majority of the patients were males $(71 \%)$ and older than 50 years
$(83.7 \%)$ with adenocarcinoma $(52.8 \%)$. Chemotherapy was the treatment for $335(59.4 \%)$ patients, and 47 different chemotherapy regimens were used. The median overall survival was 8.3 months, and $37 \%$ of the patients were alive after 1 year. ${ }^{23}$ Another observational study included 227 stage IV lung cancer patients. No epidemiological data or treatment regimen was available. The median overall survival for this group of patients was 10 months. ${ }^{24}$

There is 1 randomized, phase III trial conducted in 8 Brazilian cancer centers for frail patients with stage IV disease. A total of 205 patients with a performance status of 2 were randomized from April 2008 to July 2011 to receive pemetrexed-carboplatin or pemetrexed alone as the first line chemotherapy. The mean age was 65 years, $60 \%$ were males and the most common histology was adenocarcinoma (80\%). After a median follow-up of 27.5 months, better progression-free survival and overall survival were achieved in the pemetrexed-carboplatin arm, 5.3 months compared to 2.8 months with a single agent. The 1 -year PFS and OS, respectively, were $2 \%$ and $21.9 \%$ in the single drug arm and $17 \%$ and $40.1 \%$ in the combination arm. Grade 3 or 4 toxicities were low, but 4 deaths occurred in the more intense regimen. ${ }^{34}$

Brain is a common site for metastases and affects $\sim 40 \%$ of NSCLC patients with a poor prognosis. Few data are available about this group of patients, and there is only one report about Brazilian population. Weis et al presented the data of 70 patients with brain metastases from a university hospital at the 2016 Latin American Lung Cancer Conference. Adenocarcinoma was the most common histology; $45 \%$ of patients had a Karnofsky performance status $<70,20 \%$ had the systemic disease under control, $66 \%$ had extra cranial metastases and $37 \%$ had $>3$ brain lesions. Surgery or stereotactic radiotherapy was performed in $29 \%$ of the patients; $51 \%$ received whole brain radiation and $20 \%$ best supportive care. The median overall survival after the diagnosis of brain disease was 5.0 months, but varied significantly according to the treatment. The overall survival for patients treated with radiosurgery was 13 months, while for patients who received whole brain radiotherapy was 5.9 months and for the best supportive care population was only 0.46 months. ${ }^{35}$

\section{Targeted therapy}

Special populations with targetable specific driver molecular pathway should have an individualized treatment with target agents. The developments of these specific drugs have been a great progress in the treatment of lung cancer. Three driver mutations in NSCLC have specific treatment with a 
great increase in the outcomes when compared to cytotoxic chemotherapy. The EGFR mutation is the most common, present in $\sim 15 \%$ of lung adenocarcinoma in the USA and in up to $60 \%$ of Asians. ${ }^{36}$ Patients with this target alteration should receive first-line treatment with an anti-EGFR TKI, such as erlotinib, gefitinib or afatinib, which leads to a better response rate, progression-free survival and quality of life when compared with cytotoxic chemotherapy. ${ }^{37-40}$

The prevalence of EGFR mutation in Brazil is 25.5\%$30.4 \%$ and in Latin America is $26 \%$, but these data may not reflect the real situation of our population because of the restricted access to the test in various regions. ${ }^{41,42}$ Pontes et al reported the largest experience in screening for EGFR mutation in NSCLC, performed in an industry-sponsored access program in Brazil. Between 2011 and 2013, 3,364 samples were analyzed and 857 (25.5\%) were positive for EGFR mutation. Deletions in exon 19 were detected in 463 (54\%) of the positive samples, point mutations in exon 21 in 240 (28\%), mutations in exon 20 in $83(9.7 \%)$ and mutations in exon 18 in $71(8.3 \%)$. There are no data about the treatment outcome in these patients. ${ }^{43}$

The 2 other driver abnormalities are ALK fusion oncogene and ROS1 mutations. Usually, the population is young, with a weak history of smoking. ${ }^{44,45}$ Both alterations should be treated with crizotinib with a huge impact in progression-free survival, overall survival and quality of life. ${ }^{44,45}$ The drug is recently available in Brazil, and there are no data about this treatment in this population.

Although the knowledge of target mutation on lung cancer brings important changes in the treatment of advanced cancer, a new paradigm in the management of the disease is arriving with immunotherapy. Using the immune system to act against the tumor, new therapies, with much less toxicity and promising results, are being tested in the different clinical settings. Nivolumab and pembrolizumab, 2 anti-PD1 monoclonal antibodies, have already been approved to be used in pretreated advanced NSCLC. While all patients can be treated with nivolumab, pembrolizumab was approved to be used only in those who express PD-L1. ${ }^{46-48}$ Nivolumab has just been approved to be used in Brazil, and no data are available about the expression of PD-L1 and treatment outcome.

An important issue is that the Brazilian population is generally not represented in the clinical trials because of limited access and few research centers in the country. Probably, there are differences regarding survival and quality of life of patients treated in the community oncology center compared to those treated in the scope of clinical trials. Barrios et al evaluated the difference in the survival of stage IV lung cancer patients comparing the public health system of a Brazilian university cancer center with a research center of the same institution. Forty-one patients were treated in the public health system and 66 patients in the research center with an impressive difference. The median overall survival was 5 months and 10 months, respectively, favoring the research center treatment, with the hazard ratio of $0.6 .{ }^{49}$

\section{Discussion}

Important disparities in lung cancer care exist, not only between developing countries and high-growth economics nations, but also especially between poor and rich inhabitants of developing countries. ${ }^{50}$ Brazil has a public health system that provides treatment to the whole population. Although it provides the access to medical care for an important part of the Brazilian population, discussions regarding the quality of the service, especially to cancer patients, exist. There are evident differences between a recognizable standard of cancer care and the treatment available in the public system for the population. It is possible to point out differences from the recommendations of international guidelines in every step of the cancer care, from the diagnosis to the treatment of advanced disease. Because of the differences between the treatment within guidelines and the public services, almost $25 \%$ of the Brazilian inhabitants pay for a private health insurance. ${ }^{51}$

The Brazilian Ministry of Health published in 2014 a national guideline for cancer treatment that was developed to be the cornerstone on cancer care within the public health system. ${ }^{52}$ This document does not acknowledge the most recent developments in cancer care; thus, it is not supported or recognized by any medical society in the country, and the international guidelines from the American Society of Clinical Oncology and European Society for Medical Oncology are still the references. The gap between the international guidelines for cancer care and the resources available in the public health system does not allow the clinicians to follow important recommendations. The current existent national guideline and the standard of care practiced in the insured patients are so different and show huge treatment differences in the practice of lung cancer treatment. ${ }^{32}$

Another important fact is that the public oncology cancer centers in Brazil are not uniform regarding the technology for staging methods and images, pathologic and molecular diagnoses, drugs available for treatment and facilities for clinical support. Contrasting with this diverse and suboptimal scenario, there are great private institutions and university hospitals with massive technology and new-generation 
treatment options. Thus, it is clear that major discrepancy with the state-of-the-art patient care happens in Brazil.

The lung cancer patients under the guard of the public health system do not have as many resources and options as those under the private ones. The difficulties start in the diagnostic setting, the staging process and continue in the treatment options. An important issue is the delay in the time from the onset of symptoms until the diagnosis of lung cancer. Although the Standing Medical Advisory Committee recommends that it should take no longer than 6-8 weeks from the onset of symptoms to treatment, Knorst et a ${ }^{53}$ reported in a historical cohort a period of time superior to 140 days from the development of the first symptoms to the diagnosis of lung cancer in a university hospital in south of Brazil.

The PET/CT imaging is an important tool for staging lung cancer, but only a small fraction of patients has access to this technology. Because of its high cost and limited availability in the hospitals of public health system, it is rarely used. Furthermore, its use is only approved in the public setting for those with early disease who are potential candidates for curative surgery. Until now, there are no data about PET performed for lung cancer in Brazil. The clinical staging is mostly done with CT imaging.

Despite the existence of several biomarkers in lung cancer, limited reimbursement exists for its use. ${ }^{54}$ The EGFR mutation and the ALK fusion test are done in private laboratories, and usually, the pharmaceutical companies sponsor the test. There are no available data about these tests in the public health system, but it is estimated that $<30 \%$ of the lung adenocarcinomas are tested for EGFR and only $\sim 1 \%$ are tested for ALK fusion. Some reasons for the low rates of testing are the difficulty to have access and the cost of the test, small tissue samples of the biopsies and issues regarding limited access to the drugs needed in these scenarios. Patients diagnosed with EGFR mutation have access to anti-EGFR drugs, such as erlotinib and gefitinib, but the government reimbursement to the cancer center is only $\sim 25 \%$ of its cost. Anti-ALK fusion drug is not provided by the public health system.

Regarding the classic chemotherapy drugs, most of them can be used and guidelines can be followed. Cisplatin-vinorelbine regime is the standard of care in the adjuvant setting. ${ }^{16,17}$ Locally advanced tumors are treated with combined modality, and cisplatin-etoposide is still the most common chemotherapy regime used with radiation therapy, although the use of paclitaxel-carboplatin is increasing..$^{27,28}$ Three-dimensional conformal radiation therapy is available in many of the institutions, and 60 Gy in 6 weeks regimen established by the RTOG 7301 is the standard of care. ${ }^{55}$
Intensity-modulated radiation therapy is rarely available, and proton therapy does not exist in Brazil.

Stage IV lung cancer patients are usually treated with a platinum-doublet regime. For frail patients, single-agent docetaxel is an option. Maintenance therapy for patients with adenocarcinoma is not recommended or provided in the public system. For second line and beyond therapies, drugs commonly used include docetaxel, gemcitabine or vinorelbine. ${ }^{32}$

The oncology daily practice in the private sector is much similar to the practice in the developed countries. Patients have access to as close as possible the standard of care of international guidelines. PET/CT and brain magnetic resonance imaging are easily done for clinical staging; minimal invasive and robotic assistant procedures are available in biopsy and tissue diagnosis. In the pathology field, guidelines for molecular test are available, and an accurate histopathological diagnosis is possible to select the population to target therapy.

Despite this golden scenario in the diagnosis setting for insured patients, the same does not happen in the treatment area. Brazil is well known for delaying the approval of new therapeutics options. The last-generation chemotherapeutic agents are available, but target therapy and immunotherapy are limited. The EGFR mutation and ALK fusion test are widely available, but only first-generation anti-EGFR drugs can be easily prescribed. Although crizotinib, a first-generation anti-ALK fusion, is currently in clinical practice for $>5$ years, it was approved in Brazil only in February 2016, and the new-generation anti-ALK is not yet available in the country. Immunotherapy, such as anti-PD1 drugs, should be available in the near future for treatment of lung cancer and melanoma. Approved in early April, nivolumab and soon pembrolizumab will be available only to insured patients.

Inappropriate delay in the approval and registration of new medications in Brazil has an important impact and serious consequence on the Brazilian population. As an example, Barrios et al estimated the impact of crizotinib refusal in the registration process by the Brazilian Regulatory Agency. In a period of 3 years, the estimated 1.367 years of life would have been lost, 846 years of deterioration of life symptoms with human suffering could have happened and 772 additional patients could have remained alive if the drug was approved. ${ }^{56}$

\section{Conclusion}

The socioeconomic disparities reflected by the existence of 2 different health care systems with a restricted access to diagnosis and therapeutic methods by the largest part of the 
population pose a special and difficult task on clinical care of lung cancer patients and an enormous challenge to Brazilian health administrators. Although a high standard of care is offered to the insured patients, the majority of the population are still waiting for adequate coverage of basic products for diagnosis, evaluation and treatment of lung cancer.

\section{Disclosure}

The authors report no conflicts of interest in this work.

\section{References}

1. Siegel RL, Miller KD, Jemal A. Cancer statistics, 2015. CA Cancer J Clin. 2015;65(1):5-29.

2. Estimativa. Incidência de Câncer no Brasil [Incidence of Cancer in Brazil]. Rio de Janeiro: 2014. Available from: www.inca.gov.br. Accessed October 19, 2016. Portuguese.

3. Souza MC, Vasconcelos AG, Cruz OG. Trends in lung cancer mortality in Brazil from the 1980s into the early 21 st century: age-period-cohort analysis. Cad Saude Publica. 2012;28(1):21-30.

4. Monteiro CA, Cavalcante TM, Moura EC, Claro RM, Szwarcwald CL. Population-based evidence of a strong decline in the prevalence of smokers in Brazil (1989-2003). Bull World Health Organ. 2007;85(7):527-534.

5. Cancer INd. Global Adults Tobacco Survey Brazil 2008. 2010. Available from: www.inca.gov.br. Accessed October 19, 2016.

6. Cancer INd. Vigescola - Vigilancia de tabagismo em escolares: dados e fatos de 17 cidades brasileiras [Vigescola - smoking surveillance in school: facts and figures of 17 Brazilian cities]. 2010. Available from: http://www.inca.gov.br/vigescola/docs/vigescolafim1.pdf. Accessed September 16, 2016. Portuguese.

7. National Lung Screening Trial Research Team, Aberle DR, Adams AM, et al. Reduced lung-cancer mortality with low-dose computed tomographic screening. N Engl J Med. 2011;365(5):395-409.

8. Moyer VA, Force USPST. Screening for lung cancer: U.S. Preventive Services Task Force recommendation statement. Ann Intern Med. 2014;160(5): 330-338.

9. de Koning HJ, Meza R, Plevritis SK, et al. Benefits and harms of computed tomography lung cancer screening strategies: a comparative modeling study for the U.S. Preventive Services Task Force. Ann Intern Med. 2014;160(5):311-320.

10. Ma J, Ward EM, Smith R, Jemal A. Annual number of lung cancer deaths potentially avertable by screening in the United States. Cancer. 2013;119(7):1381-1385.

11. Takiguchi Y, Sekine I, Iwasawa S. Overdiagnosis in lung cancer screening with low-dose computed tomography. JThorac Oncol. 2013; 8(11):e101-e102.

12. dos Santos RS, Franceschini JP, Chate RC, et al. Do current lung cancer screening guidelines apply for populations with high prevalence of granulomatous disease? Results from the first Brazilian lung cancer screening trial (BRELT1). Ann Thorac Surg. 2016;101(2):481-486; discussion 487-488.

13. Ettinger DS, Wood DE, Akerley W, et al. NCCN guidelines insights: non-small cell lung cancer, version 4.2016. J Natl Compr Canc Netw. 2016;14(3):255-264.

14. Groome PA, Bolejack V, Crowley JJ, et al. The IASLC Lung Cancer Staging Project: validation of the proposals for revision of the T, N, and $\mathrm{M}$ descriptors and consequent stage groupings in the forthcoming (seventh) edition of the TNM classification of malignant tumours. J Thorac Oncol. 2007;2(8):694-705.

15. Arriagada R, Bergman B, Dunant A, et al. Cisplatin-based adjuvant chemotherapy in patients with completely resected non-small-cell lung cancer. N Engl J Med. 2004;350(4):351-360.
16. Douillard JY, Rosell R, De Lena M, et al. Adjuvant vinorelbine plus cisplatin versus observation in patients with completely resected stage IB-IIIA non-small-cell lung cancer (Adjuvant Navelbine International Trialist Association [ANITA]): a randomised controlled trial. Lancet Oncol. 2006;7(9):719-727.

17. Winton T, Livingston R, Johnson D, et al. Vinorelbine plus cisplatin vs. observation in resected non-small-cell lung cancer. NEngl J Med. 2005; 352(25):2589-2597.

18. Trodella L, Granone P, Valente S, et al. Adjuvant radiotherapy in nonsmall cell lung cancer with pathological stage I: definitive results of a phase III randomized trial. Radiother Oncol. 2002;62(1):11-19.

19. Franca LB, Oliveira MA, Small IA, Zukin M, Araujo LH. Adjuvant therapy for non-small cell lung cancer. J Bras Pneumol. 2011;37(3):354-359.

20. Araujo LH, Baldotto CS, Zukin M, et al. Survival and prognostic factors in patients with non-small cell lung cancer treated in private health care. Rev Bras Epidemiol. 2014;17(4):1001-1014.

21. Younes RN, Deutsch F, Badra C, Gross J, Haddad F, Deheinzelin D. Nonsmall cell lung cancer: evaluation of 737 consecutive patients in a single institution. Rev Hosp Clin Fac Med Sao Paulo. 2004;59(3):119-127.

22. Koshy M, Fedewa SA, Malik R, et al. Improved survival associated with neoadjuvant chemoradiation in patients with clinical stage IIIA(N2) non-small-cell lung cancer. J Thorac Oncol. 2013;8(7):915-922.

23. Eberhardt WE, Pottgen C, Gauler TC, et al. Phase III study of surgery versus definitive concurrent chemoradiotherapy boost in patients with resectable stage IIIA(N2) and selected IIIB non-small-cell lung cancer after induction chemotherapy and concurrent chemoradiotherapy (ESPATUE). J Clin Oncol. 2015;33(35):4194-4201.

24. Martins RG, Dienstmann R, de Biasi P, et al. Phase II trial of neoadjuvant chemotherapy using alternating doublets in non-small-cell lung cancer. Clin Lung Cancer. 2007;8(4):257-263.

25. Curran WJ Jr, Paulus R, Langer CJ, et al. Sequential vs. concurrent chemoradiation for stage III non-small cell lung cancer: randomized phase III trial RTOG 9410. J Natl Cancer Inst. 2011;103(19):1452-1460.

26. Schaake-Koning C, van den Bogaert W, Dalesio O, et al. Effects of concomitant cisplatin and radiotherapy on inoperable non-small-cell lung cancer. $N$ Engl J Med. 1992;326(8):524-530.

27. Albain KS, Crowley JJ, Turrisi AT 3rd, et al. Concurrent cisplatin, etoposide, and chest radiotherapy in pathologic stage IIIB non-smallcell lung cancer: a Southwest Oncology Group phase II study, SWOG 9019. J Clin Oncol. 2002;20(16):3454-3460.

28. Belani CP, Choy H, Bonomi P, et al. Combined chemoradiotherapy regimens of paclitaxel and carboplatin for locally advanced non-smallcell lung cancer: a randomized phase II locally advanced multi-modality protocol. J Clin Oncol. 2005;23(25):5883-5891.

29. Coelho JC, Piroli R, Branco MA, et al. Outcomes of chemoradiotherapy for stage III non-small-cell lung cancer in South of Brazil. World Conference on Lung Cancer; 2015; Denver, USA.

30. Besse B, Adjei A, Baas P, et al. 2nd ESMO consensus conference on lung cancer: non-small-cell lung cancer first-line/second and further lines of treatment in advanced disease. Ann Oncol. 2014;25(8):1475-1484.

31. Anelli A, Lima CA, Younes RN, Gross JL, Fogarolli R. Chemotherapy versus best supportive care in stage IV non-small cell lung cancer, non metastatic to the brain. Rev Hosp Clin Fac Med Sao Paulo. 2001;56(2):53-58.

32. Naime FF, Younes RN, Kersten BG, et al. Metastatic non-small cell lung cancer in Brazil: treatment heterogeneity in routine clinical practice. Clinics. 2007;62(4):397-404.

33. Westphal FL, Lima LC, Andrade EO, Lima Netto JC, Silva AS, Carvalho BC. Characteristics of patients with lung cancer in the city of Manaus, Brazil. J Bras Pneumol. 2009;35(2):157-163.

34. Zukin M, Barrios CH, Pereira JR, et al. Randomized phase III trial of single-agent pemetrexed versus carboplatin and pemetrexed in patients with advanced non-small-cell lung cancer and Eastern Cooperative Oncology Group performance status of 2. J Clin Oncol. 2013;31(23):2849-2853.

35. Weis LN, Coelh JC, Marks P, et al. Non-small cell lung cancer and brain metastases in Brazil. 7th Latin American Conference on Lung Câncer; 2016; Panama. 
36. Shi Y, Au JS, Thongprasert S, et al. A prospective, molecular epidemiology study of EGFR mutations in Asian patients with advanced non-small-cell lung cancer of adenocarcinoma histology (PIONEER). J Thorac Oncol. 2014;9(2):154-162.

37. Mok TS, Wu YL, Thongprasert S, et al. Gefitinib or carboplatinpaclitaxel in pulmonary adenocarcinoma. N Engl J Med. 2009;361(10): 947-957.

38. Rosell R, Carcereny E, Gervais R, et al. Erlotinib versus standard chemotherapy as first-line treatment for European patients with advanced EGFR mutation-positive non-small-cell lung cancer (EURTAC): a multicentre, open-label, randomised phase 3 trial. Lancet Oncol. 2012;13(3): 239-246.

39. Lee CK, Brown C, Gralla RJ, et al. Impact of EGFR inhibitor in non-small cell lung cancer on progression-free and overall survival: a meta-analysis. J Natl Cancer Inst. 2013;105(9):595-605.

40. Yang JC, Wu YL, Schuler M, et al. Afatinib versus cisplatin-based chemotherapy for EGFR mutation-positive lung adenocarcinoma (LUX-Lung 3 and LUX-Lung 6): analysis of overall survival data from two randomised, phase 3 trials. Lancet Oncol. 2015;16(2): 141-151.

41. Bacchi CE, Ciol H, Queiroga EM, Benine LC, Silva LH, Ojopi EB. Epidermal growth factor receptor and KRAS mutations in Brazilian lung cancer patients. Clinics. 2012;67(5):419-424.

42. Arrieta O, Cardona AF, Martin C, et al. Updated frequency of EGFR and KRAS mutations in nonsmall-cell lung cancer in Latin America: the Latin-American consortium for the investigation of lung cancer (CLICaP). J Thorac Oncol. 2015;10(5):838-843.

43. de Melo AC, de Sá VK, Sternberg C, et al. Mutational Profile and New IASLC/ATS/ERS Classification Provide Additional Prognostic Information about Lung Adenocarcinoma: A Study of 125 Patients from Brazil. Oncology. 2015;89(3):175-86.

44. Shaw AT, Solomon B. Targeting anaplastic lymphoma kinase in lung cancer. Clin Cancer Res. 2011;17(8):2081-2086.

45. Bergethon K, Shaw AT, Ou SH, et al. ROS1 rearrangements define a unique molecular class of lung cancers. J Clin Oncol. 2012;30(8): $863-870$.
46. Borghaei H, Paz-Ares L, Horn L, et al. Nivolumab versus docetaxel in advanced nonsquamous non-small-cell lung cancer. $N$ Engl J Med. 2015;373(17):1627-1639.

47. Brahmer J, Reckamp KL, Baas P, et al. Nivolumab versus docetaxel in advanced squamous-cell non-small-cell lung cancer. $N$ Engl J Med. 2015;373(2):123-135.

48. Herbst RS, Baas P, Kim DW, et al. Pembrolizumab versus docetaxel for previously treated, PD-L1-positive, advanced non-small-cell lung cancer (KEYNOTE-010): a randomised controlled trial. Lancet. 2016;387(10027): $1540-1550$

49. Barrios CH, Debiasi M, Fay AP, Viola LS, Zamprogna L, Mesa JM. Survival analysis of stage IV NSCLC patients treated by the Brazilian public health system compared with patients treated at a research center in the same institution. J Clin Oncol. 2011;29(suppl):abstre16525.

50. Baerros RPD, Foguel MN, Ulyssea G. [Income inequality in Brazil: an analysis of the recent fall]. Vol 1. Brasilia: IPEA; 2006. Portuguese.

51. Paim J, Travassos C, Almeida C, Bahia L, Macinko J. The Brazilian health system: history, advances, and challenges. Lancet. 2011;377(9779): 1778-1797.

52. Brasil. Protocolos Clínicos e Diretrizes Terapêuticas em Oncologia [Brazil. Clinical Protocols and Therapeutic Guidelines in Oncology]. Brasília: Ministério da Saúde; 2014. Portuguese.

53. Knorst MM, Dienstmann R, Fagundes LP. Retardo no diagnóstico e no tratamento cirúrgico do câncer de pulmão [Delay in the diagnosis and in the surgical treatment of lung cancer]. J Pneumol. 2003;29(6): 358-364. Portuguese.

54. Tsao AS, Scagliotti GV, Bunn PA Jr, et al. Scientific advances in lung cancer 2015. J Thorac Oncol. 2016;11(5):613-638.

55. Perez CA, Stanley K, Rubin P, et al. A prospective randomized study of various irradiation doses and fractionation schedules in the treatment of inoperable non-oat-cell carcinoma of the lung. Preliminary report by the Radiation Therapy Oncology Group. Cancer. 1980;45(11):2744-2753.

56. Barrios P, Debiasi M, Lopes G, BARRIOS CX. Impact of regulatory delays in approving oncology drugs in a developing country: mortality associated with lack of access to crizotinib in Brazil. World Conference on Lung Cancer; 2015; Denver, Colorado.
Lung Cancer: Targets and Therapy

\section{Publish your work in this journal}

Lung Cancer: Targets and Therapy is an international, peer-reviewed, open access journal focusing on lung cancer research, identification of therapeutic targets and the optimal use of preventative and integrated treatment interventions to achieve improved outcomes, enhanced survival and quality of life for the cancer patient. Specific topics covered in the journal include: Epidemiology, detection and screening; Cellular research and biomarkers; Identification of biotargets and agents with novel Submit your manuscript here: https://www.dovepress.com/lung-cancer-targets--therapy-journal

\section{Dovepress}

mechanisms of action; Optimal clinical use of existing anticancer agents, including combination therapies; Radiation and surgery; Palliative care; Patient adherence, quality of life, satisfaction; Health economic evaluations. The manuscript management system is completely online and includes a very quick and fair peer-review system. Visit http://www.dovepress.com/testimonials.php to read real quotes from published authors. 